\title{
Paraneoplastic necrotizing myopathy in association with metastatic malignant melanoma: two case reports and a review of the literature
}

\begin{abstract}
Molly S Peterson ${ }^{1}$, Bjoern Buehring ${ }^{2}$, Patrick S Rush ${ }^{3}$, Sara R Fitz ${ }^{4}$, Mark R Albertini ${ }^{5}$
1. University of Wisconsin School of Medicine and Public Health, Madison, WI, United States. 2. Department of Medicine, University of Wisconsin School of Medicine and Public Health; William S. Middleton Memorial Veterans Hospital; Madison, WI, United States. 3. Department of Pathology and Laboratory Medicine, University of Wisconsin School of Medicine and Public Health, Madison, WI, United States. 4. Department of Dermatology, University of Wisconsin School of Medicine and Public Health, Madison, WI, United States. 5. Department of Medicine, University of Wisconsin School of Medicine and Public Health; University of Wisconsin Carbone Cancer Center; William S. Middleton Memorial Veterans Hospital; Madison, WI, United States.
\end{abstract}

Correspondence: Mark R Albertini. Address: University of Wisconsin Carbone Cancer Center, 600 Highland Ave, K6/530, Department of Medicine, Madison, WI 53792, United States. E-mail: mralbert@wisc.edu

Received: April 17, 2015

DOI : $10.5430 /$ crcp.v2n4p46

Online Published: July 28, 2015

\section{Abstract}

Necrotizing myopathy is a rare subtype of inflammatory myopathy characterized predominantly by muscle weakness without inflammation. While the association of malignancy and inflammatory myopathies such as dermatomyositis and polymyositis is well-recognized, necrotizing myopathy has rarely been reported in association with cancer and, to our knowledge, has not been previously reported in association with melanoma. We report two cases of necrotizing myopathy in association with metastatic malignant melanoma.

\section{Key words}

Necrotizing myopathy, Paraneoplastic syndromes, Metastatic malignant melanoma

\section{Introduction}

Inflammatory myopathies are a heterogeneous group of autoimmune disorders, predominantly affecting the skeletal muscles. Discrete subcategories of inflammatory myopathy are distinguished on the basis of clinical presentation (see Table 1), laboratory findings (see Table 2), and pathological differences (see Table 3$)^{[1-3]}$. The three most common subgroups are polymyositis, dermatomyositis, and inclusion body myositis. Necrotizing myopathy is a rare emerging entity that is a unique progressive myopathy with distinct pathologic features, specifically necrosis with limited or absent inflammatory infiltrate ${ }^{[1]}$. The association between malignancy and inflammatory myopathies is commonly reported in dermatomyositis and polymyositis, and to a much lesser extent in necrotizing myopathy. Dermatomyositis has the strongest association with ovarian, lung, pancreatic, gastric, colorectal, and nasopharyngeal cancers, while polymyositis is more frequently associated with non-Hodgkin lymphoma, lung, and bladder cancers ${ }^{[4]}$. We present two cases of necrotizing myopathy in association with malignant melanoma and provide a brief review of idiopathic inflammatory myopathies. 
Table 1. Clinical presentation of inflammatory myopathies

\begin{tabular}{|c|c|c|c|c|}
\hline & Dermatomyositis & Polymyositis & Inclusion body myositis & $\begin{array}{l}\text { Necrotizing autoimmune } \\
\text { myopathy }\end{array}$ \\
\hline Age of onset & All ages & Adults $>18$ years & Adults $>50$ years & Adults $>18$ years and elderly \\
\hline Gender & Women $>$ men & Women $>$ men & Men $>$ women & Unknown \\
\hline $\begin{array}{l}\text { Affected } \\
\text { muscles }\end{array}$ & Proximal $>$ distal & Proximal $>$ distal & $\begin{array}{l}\text { Distal > proximal (quadriceps, } \\
\text { forearm flexors, ankle dorsiflexors) }\end{array}$ & Proximal $>$ distal \\
\hline $\begin{array}{l}\text { Pattern of } \\
\text { weakness }\end{array}$ & Bilateral & Bilateral & Asymmetrical & Bilateral \\
\hline Rash & Yes & No & No & No \\
\hline Arthralgias & $+/-$ & $+/-$ & $+/-$ & $+/-$ \\
\hline Dysphagia & $+/-$ & $+/-$ & $+/-$ & $+/-$ \\
\hline $\begin{array}{l}\text { Commonly } \\
\text { associated } \\
\text { conditions }\end{array}$ & $\begin{array}{l}\text { Malignancy, } \\
\text { myocarditis, ILD, CTD, } \\
\text { vasculitis }\end{array}$ & $\begin{array}{l}\text { Malignancy, } \\
\text { myocarditis, ILD, } \\
\text { CTD }\end{array}$ & CTD & $\begin{array}{l}\text { Malignancy, CTD, } \\
\text { drug-induced }\end{array}$ \\
\hline
\end{tabular}

Note. ILD, interstitial lung disease; CTD, connective tissue disease.

Table 2. Laboratory workup of inflammatory myopathies

\begin{tabular}{|c|c|c|c|c|}
\hline & Dermatomyositis & Polymyositis & Inclusion body myositis & $\begin{array}{l}\text { Necrotizing } \\
\text { autoimmune } \\
\text { myopathy }\end{array}$ \\
\hline Creatine kinase & $\begin{array}{l}\text { Normal or increased up to } \\
50 \times \text { normal }\end{array}$ & Increased up to $50 \times$ normal & $\begin{array}{l}\text { Normal or increased up to } \\
15-20 \times \text { normal }\end{array}$ & $\begin{array}{l}\text { Increased up to } 10 \times \\
\text { normal }\end{array}$ \\
\hline $\begin{array}{l}\text { Most commonly } \\
\text { described } \\
\text { myositis-specific } \\
\text { auto-antibodies }\end{array}$ & $\begin{array}{l}\text { Anti-Jo-1; anti-Mi-2; } \\
\text { anti-MDA5; anti-TIF1- } \gamma \\
\text { (anti-p155); anti-NXP-2 }\end{array}$ & Anti-PM-Scl; anti-Jo-1 & $\begin{array}{l}\text { Anti-M-protein; } \\
\text { anti-NT5C1A } \\
\text { (anti-mup44) }\end{array}$ & $\begin{array}{l}\text { Anti-SRP; } \\
\text { anti-HMG-CoA } \\
\text { reductase }\end{array}$ \\
\hline EMG findings & $\begin{array}{l}\text { Short duration polyphasic } \\
\text { motor unit action } \\
\text { potentials; spontaneous } \\
\text { fibrillations, sharp waves, } \\
\text { and/or repetitive } \\
\text { discharges }\end{array}$ & $\begin{array}{l}\text { Mild sensory axon loss } \\
\text { peripheral polyneuropathy in } \\
30 \% \text { of patients; short duration } \\
\text { polyphasic motor unit action } \\
\text { potentials; spontaneous } \\
\text { fibrillations, sharp waves, } \\
\text { and/or repetitive discharges }\end{array}$ & $\begin{array}{l}\text { Short duration polyphasic } \\
\text { motor unit action } \\
\text { potentials; spontaneous } \\
\text { fibrillations, sharp waves, } \\
\text { and/or repetitive } \\
\text { discharges }\end{array}$ & $\begin{array}{l}\text { Short duration } \\
\text { polyphasic motor unit } \\
\text { action potentials; } \\
\text { spontaneous } \\
\text { fibrillations, sharp } \\
\text { waves, and/or repetitive } \\
\text { discharges }\end{array}$ \\
\hline
\end{tabular}

Note. Not all auto-antibodies that can occur in inflammatory myopathies are listed but rather the most commonly described are highlighted. MI-2, mitochondrial antigen 2; MDA5, melanoma differentiation-associated protein 5; TIF1- $\gamma$, transcriptional intermediary factor 1 gamma; NXP-2, nuclear matrix protein 2; PM-Scl, polymyositis-scleroderma; NT5C1A, cytosolic 5'-nucleotidase IA; SRP, signal recognition particle; HMG-CoA reductase; 3-hydroxy-3-methyl-glutaryl-CoA reductase.

Table 3. Pathology and treatment of inflammatory myopathies

\begin{tabular}{lllll}
\hline & Dermatomyositis & Polymyositis & $\begin{array}{l}\text { Inclusion body } \\
\text { myositis }\end{array}$ & $\begin{array}{l}\text { Necrotizing autoimmune } \\
\text { myopathy }\end{array}$ \\
\hline $\begin{array}{l}\text { Cellular } \\
\text { infiltrate }\end{array}$ & T cells (CD4>CD8); B cells & $\begin{array}{l}\text { T cells (CD8 }>\text { CD4) that } \\
\text { express MHC-I antigens; } \\
\text { macrophages }\end{array}$ & $\begin{array}{l}\text { T cells (CD8>CD4) } \\
\text { that express MHC-I } \\
\text { antigens; macrophages }\end{array}$ & $\begin{array}{l}\text { Macrophages; little to no } \\
\text { lymphocytes }\end{array}$ \\
$\begin{array}{l}\text { Degree of } \\
\text { inflammation }\end{array}$ & Prominent & Prominent & Prominent & Sparse \\
$\begin{array}{l}\text { Characteristic } \\
\text { findings }\end{array}$ & $\begin{array}{l}\text { Perifasicular atrophy, muscle } \\
\text { infarcts, and capillary necrosis } \\
\text { with MAC deposition on }\end{array}$ & $\begin{array}{l}\text { Endomysial } \\
\text { inflammation } \\
\text { surrounding non- } \\
\text { necrotic muscle fibers }\end{array}$ & $\begin{array}{l}\text { Endomysial } \\
\text { inflammation with } \\
\text { rimmed vacuoles }\end{array}$ & $\begin{array}{l}\text { Necrotic myofibers with little } \\
\text { to no inflammatory infiltrate; } \\
\text { capillaries may be seen }\end{array}$ \\
$\begin{array}{l}\text { Response to } \\
\text { glucocorticoids }\end{array}$ & Frequent & Frequent & Infrequent & Occasional \\
\hline
\end{tabular}

Note. MHC, major histocompatibility complex; MAC, membrane attack complex. 


\section{Case presentation}

\subsection{Patient 1}

In April of 2006, a 53-year-old white man (Patient 1) noticed a small palpable purple lesion on the posterior aspect of his head, which was irritated by his daily headwear. He was seen clinically and was found to have an $8 \mathrm{~mm}$ pigmented papule that was thought to be an acquired compound nevus. Biopsy of the lesion found it to be a nodular melanoma arising in a pre-existing nevus. The melanoma was a T3b scalp melanoma, and management with wide local excision and lymph node neck dissection that demonstrated 2 of 46 lymph nodes to be positive for melanoma. The metastatic workup was negative, and he received treatment with adjuvant interferon alfa-2b (Intron-A) for approximately one year. Patient 1 had a biopsy confirmed metastases in 2009. His subsequent management included temozolomide, regional surgery, regional radiotherapy, and additional treatment with temozolomide before referral to the University of Wisconsin-Madison in August, 2010. Patient 1 participated in CO08604: Phase I Study To Evaluate the Toxicity and Feasibility of Intratumoral Injection of Alpha-Gal Glycolipids In Patients With Advanced Melanoma ${ }^{[5]}$. He received two separate intra-tumoral injections of $0.1 \mathrm{mg}$ of alpha-gal glycolipids without significant toxicity on September 14, 2010 and October 12, 2010, respectively. The disease assessment 4 weeks after the second injection of alpha-gal glycolipids revealed stable disease, and the plan was for clinical monitoring.

Beginning in March of 2011, Patient 1 had a significant increase in alanine transaminase (ALT) and aspartate aminotransferase (AST; see Table 4). These levels persisted and a liver biopsy in June of 2011 revealed chronic hepatitis, grade 1 . The impression was that this was most likely a medication-induced hepatitis rather than an autoimmune process as the biopsy results did not show any interface hepatitis or fibrosis.

Table 4. Patient 1 laboratory findings

\begin{tabular}{llll}
\hline Date & CK (reference range: 28-260 U/L) & ALT (reference range: 0-65 U/L) & AST (reference range: 0-50 U/L) \\
\hline $05-11$ & & 139 & 106 \\
$09-02-11$ & 4699 & 207 & 138 \\
$10-07-11$ & 5005 & & \\
$11-04-11$ & 3303 & & \\
$12-02-11$ & 5471 & & \\
\hline
\end{tabular}

Note. CK, creatine kinase; ALT, alanine aminotransferase; AST, aspartate aminotransferase.

Patient 1 had significant disease progression in July 2011 including focal bowel wall thickening consistent with bowel metastasis. Patient 1 continued with a persistent increase in AST and ALT and developed worsening fatigue, muscle weakness, and whole-body arthralgias. An evaluation by Neurology in August of 2011 identified progressive right upper extremity weakness with widespread atrophy of muscles in the right upper extremity (supraspinatus, pectoralis muscle, deltoid muscle, and proximal biceps and triceps muscles). A muscle biopsy demonstrated multiple scattered necrotic myofibers with occasional infiltration of macrophages (see Figure 1), as well as the rare regenerating fiber. Additionally, a lymphocytic infiltration or vasculitis was not present. The slides were reviewed by a board certified neuropathologist, and two fellowship trained neurologists/mycologists who agreed there were no findings of an auto-aggressive inflammatory infiltrate. The diagnosis was necrotizing myopathy consistent with a paraneoplastic necrotizing myopathy. Laboratory findings are provided in Table 4.

An earlier melanoma tumor biopsy demonstrated the BRAF V600E mutation, and Patient 1 started vemurafenib (Zelboraf) in September of 2011. While this treatment obtained an initial decrease in tumor burden, Patient 1 experienced continued muscle weakness. The CK levels remained elevated (see Table 4). Vemurafenib was stopped in December of 2011 due to progressive disease. The CK was $5471 \mathrm{U} / \mathrm{L}$ on December 2, 2011. Patient 1 continued to have progressive generalized weakness that was disabling, and he joined hospice in January of 2012 before his death due to metastatic melanoma. 


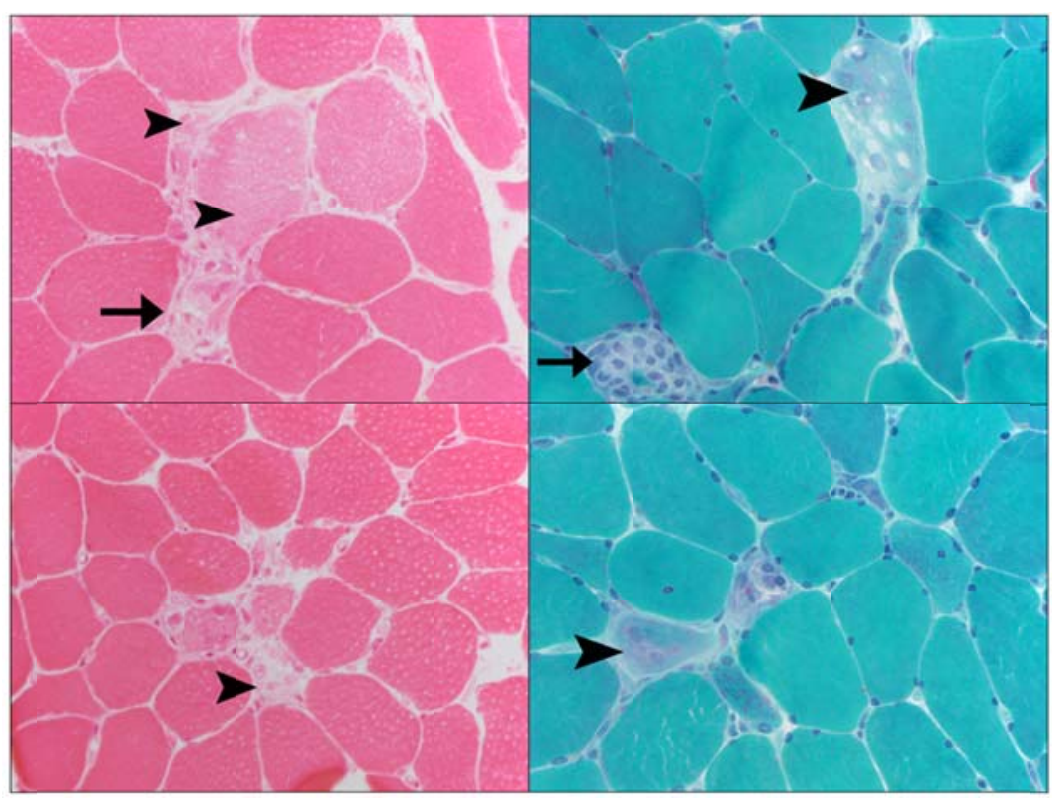

Figure 1. H\&E (left), and Trichrome (right) stains of muscle biopsy from Patient 1, demonstrating multiple scattered necrotic muscle fibers (arrowheads), some of which are infiltrated by macrophages and the absence of lymphocytic infiltrate (arrows). Original magnification, 400×.

\subsection{Patient 2}

In March of 2006, a 43-year-old man (Patient 2) with a past medical history of recurrent deep vein thrombosis, pulmonary embolism, and lupus anticoagulant was referred for a concerning pigmented lesion by the left dorsal foot. Excisional biopsy revealed a T1b malignant melanoma, pleomorphic type. Management with wide local excision and sentinel lymph node biopsy was negative. He was followed clinically without evidence of recurrence until September of 2012 when CT imaging revealed pelvic lymphadenopathy. A CT-guided biopsy of a retroperitoneal lymph node demonstrated malignant melanoma that was BRAF V600E mutation positive. Imaging also revealed deep inguinal and para-aortic adenopathy. Patient 2 reported malaise, lower extremity weakness, myalgias, and mild dysphagia. Laboratory workup in October 2012 revealed a markedly elevated value of CK (see Table 5). The ANA, rheumatoid factor, anti-Jo-1, anti-Smith, and anti-RNP were negative. The ANCA total autoantibody was less than 1:20.

Table 2. Patient 2 laboratory findings

\begin{tabular}{llll}
\hline Date & CK (reference range: 28-260 U/L) & ALT (reference range: 0-65 U/L) & AST (reference range: 0-50 U/L) \\
\hline $10-12-12$ & 4549 & 111 & 87 \\
$11-07-12$ & 4218 & & \\
$05-20-13$ & 125 & & \\
$07-19-13$ & 290 & & \\
$09-11-13$ & 416 & & \\
$10-18-13$ & 167 & & \\
$12-02-13$ & 62 & & \\
$03-07-14$ & 48 & & \\
$04-25-14$ & 79 & & \\
$05-16-14$ & 181 & & \\
$06-13-14$ & 304 & & \\
$07-11-14$ & 551 & & \\
$08-15-14$ & 2284 & & \\
$09-12-14$ & 1050 & & \\
\hline
\end{tabular}

Note. CK, creatine kinase; ALT, alanine aminotransferase; AST, aspartate aminotransferase. 
A muscle biopsy in December of 2012 identified randomly distributed necrotic muscle fibers infiltrated by macrophages that did not appear to involve an auto-aggressive inflammatory cell infiltrate (see Figure 2). There was some mild lymphocytic infiltration in the endomysium as well as in the perimysium. The lymphocytic infiltration was not in direct associated with necrotic myocytes, and the infiltrate was further characterized by immunohistochemistry (IHC). The inflammatory infiltrate was evaluated for CD4, CD3, CD8, and CD20, and it was shown to be primarily composed of T cells $(\mathrm{CD} 4>\mathrm{CD} 8)$, with scant $\mathrm{B}$ cells. This histologic picture was interpreted as representing a necrotizing myopathy.

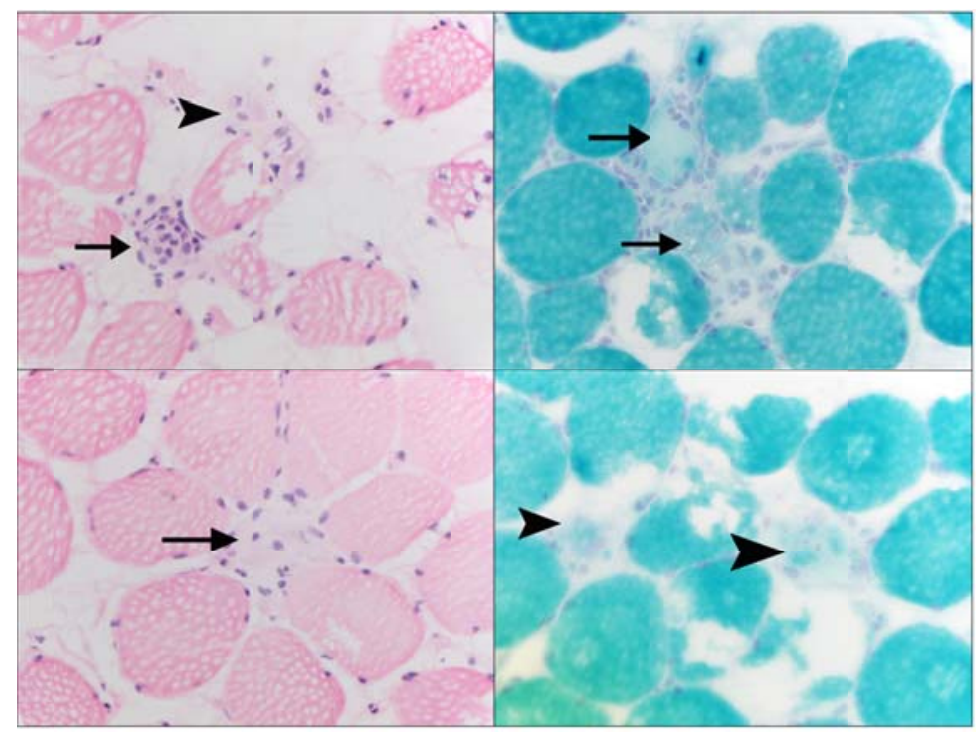

Figure 2. Frozen H\&E (left), and Trichrome (right) stains of muscle biopsy from Patient 2 demonstrating, randomly distributed necrotic myofibers (arrowheads) occasionally infiltrated by macrophages (arrows). There is an absence of an inflammation pattern where lymphocytes are attacking muscle fibers.

From November 2012 to January 2013, Patient 2 was treated with vemurafenib. Though this significantly decreased the tumor burden, he had considerable treatment-associated toxicities requiring dose reductions and ultimately treatment discontinuation. Notably, the elevated CK did decrease with vemurafenib (see Table 5). In February of 2013, he had a superficial and deep left inguinal and iliac lymph node dissection that revealed metastatic melanoma in 3 of 22 lymph nodes.

In July of 2013, PET/CT imaging noted new hypermetabolic left periaortic, aortocaval, and bilateral iliac adenopathy, prompting treatment with dabrafenib (Tafinlar). The myopathy flared at that time and Patient 2 was treated with a course of prednisone with improvement in his myalgias (see Table 5 for laboratory values). Imaging revealed reduction of the previously enlarged lymph nodes. Treatment-associated toxicities including arthralgias, diffuse morbiliform eruption, fatigue, alopecia, and hand-foot syndrome with associated pain resulted in dabrafenib dose reductions. Dabrafenib was then discontinued in April 2014 due to progressive disease. Patient 2 also experienced progressive fatigue and dysphagia. He was initiated on trametinib (Mekinist), a MEK inhibitor, in July 2014. However, Patient 2 continued to experience myalgias, arthralgias, and proximal muscle weakness. His CK continued to increase on August 15, 2014 (see Table 5). He was started on a course of prednisone on August 19, 2014 with some improvement in these symptoms. His disease evaluation on September 12, 2014 revealed continued progression of metastatic melanoma. He was then referred for high-dose interleukin-2, but had continued disease progression before his death due to metastatic melanoma.

\section{Material and methods}

Fresh tissue was obtained from muscle biopsies. Muscle tissue was received at the UWHC Neuromuscular laboratory, where the specimens were grossed in accordance with institutional methods and divided into segments if needed for 
histochemistry, biochemistry, and electron microscopy. Frozen section was completed and tissue sections were stained with hematoxalin and eosin (H\&E), trichrome, periodic acid-schiff (PAS), oil red O, and congo red. Enzyme histochemistry for NADH, cytochrome c oxidase, cytochrome c oxidase with SDH, ATP at pHs 4.6, 4.3, and 9.4, acid phosphatase, nonspecific esterase, and myophosphatase. Immunohistochemistry was performed where necessary: $4 \mu \mathrm{m}$ sections were rinsed and stained with hematoxalin and processed in a VENTANA Benchmark Ultra IHC stainer. Cases were reviewed by a board certified neuropathologist, and two fellowship trained neurologists/mycologists.

The reporting of medical cases of three or fewer patients is not considered human subjects research by the University of Wisconsin-Madison Health Sciences IRB and is therefore exempt from IRB review at the University of WisconsinMadison.

\section{Discussion}

Necrotizing myopathy is a rare subgroup of inflammatory myopathies characterized by necrosis with little to no inflammatory infiltrate. Specific subtypes of necrotizing myopathy may be associated with toxins, HMG-CoA reductase inhibitors or "statins", thick pipe stem capillaries on muscle biopsy, auto-antibodies to the signal recognition particle (SRP), underlying malignancy, or may be, by exclusion, idiopathic ${ }^{[6]}$. The histologic picture that was seen within the muscle biopsies of these patients was that of a necrotizing myopathy. This histologic picture would be consistent with a number of etiologies including exposure to toxins, viral reactions, medication exposure, and a paraneoplastic syndrome. We reviewed the literature for possible agents related to necrotizing myopathy and found multiple agents including statins, fibrates, e-aminocaproic acid, cyclosporine, labetalol, propofol, organophosphate poisoning, and alcohol ${ }^{[2]}$. Although it is impossible to prove that these myopathies were not related to drug/toxin exposure, our chart review did not show that Patient 1 or Patient 2 had any significant exposure to any of these agents at the time they developed necrotizing myopathy. In addition, the necrotizing myopathy diagnosis of Patient 1 was considered unlikely to be related to the patient's prior treatment with alpha-gal glycolipids due to 1) delayed timing related to prior protocol therapy; 2) lack of an inflammatory cell infiltrate in the muscle biopsy; and 3) lack of detectable autoantibodies to striated muscle. While we cannot exclude a role for other agents in causing the necrotizing myopathy, the association with progression of metastatic melanoma is consistent with a paraneoplastic effect.

The classic clinical finding of necrotizing myopathy is symmetrical proximal muscle weakness without a rash ${ }^{[7,8]}$. Symptoms may mimic polymyositis, however, necrotizing myopathy progresses more rapidly and is more marked in severity in $30 \%$ of cases ${ }^{[9]}$. The most severely affected muscles are the proximal shoulder girdle muscles, though neck flexors, pharyngeal muscles, and respiratory muscles may also be involved ${ }^{[6]}$. Other manifestations include fatigue, dyspnea, myalgias and dysphagia ${ }^{[2]}$. The disease course is variable, with outcomes ranging from rapid progression to complete recovery.

Muscle enzyme abnormalities, particularly elevated CK and aldolase, are characteristic of inflammatory myopathies, and may be the first indication of disease. In necrotizing myopathy, serum CK levels are regularly increased more than 10 times the upper normal limit. By comparison, CK is usually elevated 5 to 50 times the upper limit in polymyositis, and is increased up to 50 -fold in dermatomyositis, though $10 \%$ of patients have normal $\mathrm{CK}$ regardless of severity ${ }^{[1]}$. Compared to non-paraneoplastic myopathy, paraneoplastic myopathy is more often associated with a dramatically elevated CK level ${ }^{[7]}$.

Muscle biopsy is essential for the diagnosis of necrotizing myopathy. The hallmark of this condition histologically, is the presence of scattered necrotic and regenerative myofibers, with little to no inflammatory infiltrate except myophagocytosis. Paraneoplastic necrotizing myopathies are histopathologically heterogeneous, ranging from sparse to massive necrosis, and may have a mild inflammatory component ${ }^{[10]}$. Some cases have demonstrated thickened and hyalinized capillaries, called pipestem capillaries, and complement membrane attack complex deposition in endomysial 
capillaries ${ }^{[11]}$. The absence of inflammatory infiltrate allows necrotizing myopathy to be distinguished from other inflammatory myopathies (see Table 3). The histopathologic findings of our patients are most consistent with a necrotizing myopathy. Mild inflammation away from necrotic myocytes, in the endomysium of one of our subjects supports the view that paraneoplastic necrotizing and inflammatory myopathy might represent a continuum of a condition with varying degrees of inflammation and necrosis ${ }^{[10]}$.

Myositis-specific auto-antibodies have also been described and influence the phenotype of the inflammatory myopathy ${ }^{[1,3,12]}$. Antibodies directed against SRP and HMG-CoA reductase are characteristic of necrotizing myopathy. Anti-SRP subjects have unique clinical features, including more severe myopathy with dysphagia, very high CK levels, and better response to steroid therapy ${ }^{[3]}$. Two recent case series have suggested that anti-SRP levels do correlate with disease severity, and may serve as a marker of poor prognosis ${ }^{[13,14]}$. Additionally, a recent study identified anti-HMGCoA reductase autoantibodies in $63 \%$ of patients with necrotizing autoimmune myopathy ${ }^{[15]}$. These antibodies are more frequently found in patients with statin-associated necrotizing myopathy, and less frequently in statin-unexposed subjects ${ }^{[16]}$. Our patients were not tested for specific markers of necrotizing myopathy.

The increased risk of malignancy in patients with inflammatory myopathies such as dermatomyositis and polymyosistis is well-recognized, with prevalence ranging from $6 \%$ to $45 \%{ }^{[17]}$. Necrotizing myopathy, however, has rarely been reported in association with cancer in the literature. We performed a literature search using combinations of the keywords necrotizing myopathy, inflammatory myopathy, malignancy, paraneoplastic, and melanoma. The most commonly associated cancer types were gastrointestinal tract adenocarcinoma, prostate adenocarcinoma, bladder cancer, and nonsmall cell lung cancer ${ }^{[18]}$. Our search yielded no reports of necrotizing myopathy in association with malignant melanoma. To the best of our knowledge, our patients represent the first two reported cases of necrotizing myopathy in association with BRAF mutant metastatic malignant melanoma.

Paraneoplastic necrotizing myopathy differs from primary myopathies in that prognosis is primarily dependent upon characteristics of the underlying malignancy ${ }^{[7]}$. Thus, treatment directed against the underlying malignancy is critical. Immunosuppressive therapy and corticosteroids, such as prednisone, are generally effective in the treatment of inflammatory myopathies; however, necrotizing myopathy is commonly more resistant to treatment than polymyositis or dermatomyositis. These patients more often require aggressive, long-term immunotherapy with multiple immunesuppressive agents ${ }^{[19]}$. Additional treatment with intravenous immunoglobulins, monoclonal antibodies, and immune modulators may also be beneficial to some patients ${ }^{[10]}$. Interestingly, treatment responses vary among patients, and the severity of the condition does not always parallel tumor progression ${ }^{[20]}$. Necrotizing myopathy has been reported to be responsive to treatment when the tumor is controlled ${ }^{[18]}$.

The underlying etiology of paraneoplastic syndromes remains unclear, though response to steroids is most compatible with an autoimmune-mediated process ${ }^{[10]}$. Some postulate that paraneoplastic syndromes are an immunologic response to the tumor, invoking autoimmunity in immunologically predisposed patients ${ }^{[21,22]}$. Immune responses generated against antigens expressed by the tumor may unintentionally cross-react with skin and muscle cells expressing the same antigens. This theory is supported by the expression of common auto-antigens in myositis and certain malignancies ${ }^{[22]}$. Furthermore, the absence of inflammation in necrotizing myopathy suggests that humoral mechanisms may be responsible for inducing necrosis, and argues against a pathogenic role for cytotoxic lymphocytes ${ }^{[23]}$.

In summary, we have presented two cases of necrotizing myopathy in association with BRAF mutant metastatic malignant melanoma. The first case had progressive myopathy that did not respond to BRAF inhibitor therapy, while the second case remitted with BRAF inhibitor therapy and recurred with subsequent disease progression. To our knowledge, these are the first two reported cases of necrotizing myopathy in association with malignant melanoma. These cases highlight the importance of a muscle biopsy in patients with a suspected myopathy because the different types of myopathies can often not be distinguished clinically, through imaging or laboratory testing. It appears that the most important management 
approach for necrotizing myopathy is to treat the underlying disease. Because the association between necrotizing myopathy and cancer is rare, this finding should prompt a search for underlying malignancy if no other cause can be identified.

\section{Acknowledgements}

We thank the Herman and Gwendolyn Shapiro Foundation and the Department of Medicine of the University of Wisconsin School of Medicine and Public Health for supporting Molly Peterson with a Shapiro summer research award for this study.

\section{References}

[1] Dimachkie MM, Barohn RJ, Amato AA. Idiopathic inflammatory myopathies. Neurol Clin. 2014; 32: 595-628. PMid: 25037081. http://dx.doi.org/10.1016/j.ncl.2014.04.007

[2] Khan S, Christopher-Stine L. Polymyositis, dermatomyositis, and autoimmune necrotizing myopathy: clinical feature. Rheum Dis Clin N Am. 2011; 37: 143-158. PMid: 21444016. http://dx.doi.org/10.1016/j.rdc.2011.01.001

[3] Casciola-Rosen L, Mammen AL. Myositis autoantibodies. Curr Opin Rheumatol. 2012; 24(6): 602-608. PMid: 22955022. http://dx.doi.org/10.1097/BOR.0b013e328358bd85

[4] Azar L, Khasnis A. Paraneoplastic rheumatologic syndromes. Curr Opin Rheumatol. 2013; 25(1): 44-49. PMid: 23026875. http://dx.doi.org/10.1097/BOR.0b013e328359e780

[5] Galili U, Albertini MR, Sondel PM, et al. In situ conversion of melanoma lesions into autologous vaccine by intratumoral injections of $\alpha-\gamma \alpha \lambda$ glycolipids. Cancers. 2010; 2: 773-793. PMid: 23087817. http://dx.doi.org/10.3390/cancers2020773

[6] Liang C, Needham M. Necrotizing autoimmune myopathy. Curr Opin Rheumatol. 2011; 23: 612-619. PMid: 21885975. http://dx.doi.org/10.1097/BOR.0b013e32834b324b

[7] Acciavatti A, Avolio T, Rappuoli S, et al. Paraneoplastic necrotizing myopathy associated with adenocarcinoma of the lung - a rare entitiy with atypical onset: a case report. J Med Case Reports. 2013; 7: 112. PMid: 23618006. http://dx.doi.org/10.1186/1752-1947-7-112

[8] Aggarwal R, Oddis CV. Paraneoplastic myalgias and myositis. Rheum Dis Clin N Am. 2011; 37(4): 607-621. PMid: 22075200. http://dx.doi.org/10.1016/j.rdc.2011.09.007

[9] van der Meulen MF, Bronner IM, Hoogendijk JE, et al. Polymyositis: an overdiagnosed entity. Neurology. 2003; 61(3): 316-321. PMid: 12913190. http://dx.doi.org/10.1212/WNL.61.3.316

[10] Wegener S, Bremer J, Komminoth P, et al. Paraneoplastic necrotizing myopahty with a mild inflammatory component: a case report and review of the literature. Case Rep Oncol. 2010; 3: 88-92. PMid: 20740165. http://dx.doi.org/10.1159/000308714

[11] Emslie-Smith AM, Engel AG. Necrotizing myopathy with pipestem capillaries, microvascular deposition of the complement membrane attack complex (MAC), and minimal cellular infiltration. Neurology. 1991; 41: 936-939. PMid: 2046947. http://dx.doi.org/10.1212/WNL.41.6.936

[12] Love LA, Leff RL, Fraser DD, et al. A new approach to the classification of idiopathic inflammatory myopathy: myositis-specific autoantibodies define useful homogenous patient groups. Medicine. 1991; 70: 360-374. PMid: 1659647. http://dx.doi.org/10.1097/00005792-199111000-00002

[13] Benveniste O, Drouot L, Jouen F, et al. Correlation of anti-signal recognition particle autoantibody levels with creatine kinase activity in patients with necrotizing myopathy. Arthritis Rheum. 2011; 63(7): 1961-1971. PMid: 21400483. http://dx.doi.org/10.1002/art.30344

[14] Valiyil R, Casciola-Rosen L, Hong G, et al. Rituximab therapy for myopathy associated with anti-signal recognition particle antibodies: a case series. Arthritis Care Res. 2010; 62(9): 1328-1334. PMid: 20506493. http://dx.doi.org/10.1002/acr.20219

[15] Christopher-Stine L, Casciola-Rosen LA, Hong G, et al. A novel autoantibody recognizing 200-kd and 100-kd proteins is associated with an immune-mediated necrotizing myopathy. Arthris Rheum. 2010; 62(9): 2757-2766. PMid: 20496415. http://dx.doi.org/10.1002/art.27572

[16] Werner JL, Christopher-Stine L, Ghazarian SR, et al. Antibody levels correlate with creatine kinase levels and strength in anti-HMG-CoA reductase-associated autoimmune myopathy. Arthritis Rheum. 2012; 64(12): 4087-4093. PMid: 22933019. http://dx.doi.org/10.1002/art.34673

[17] Maoz CR, Langevitz P, Livneh A, et al. High incidence of malignancies in patients with dermatomyositis and polymyositis: an 11-year analysis. Semin Arthritis Rheum. 1998; 27: 319-324. http://dx.doi.org/10.1016/S0049-0172(98)80052-8 
[18] Levin MI, Mozaffar T, Al-Lozi MT, et al. Paraneoplastic necrotizing myopathy: clinical and pathologic features. Neurology. 1998; 50: 764-767. PMid: 9521271. http://dx.doi.org/10.1212/WNL.50.3.764

[19] Grable-Esposito P, Katzberg HD, Greenberg SA, et al. Immune-mediated necrotizing myopathy associated with statin. Muscle Nerve. 2010; 41: 185-190. PMid: 19813188.

[20] Sampson JB, Smith SM, Smith AG, et al. Paraneoplastic myopathy: response to intravenous immunoglobulin. Neuromuscul Disord. 2007; 17: 404-408. PMid: 17336069. http://dx.doi.org/10.1016/j.nmd.2007.01.004

[21] Callen JP. Relationship of cancer to inflammatory muscle diseases: dermatomyositis, polymyositis, and inclusion body myositis. Rheum Dis Clin North Am. 1994; 20: 943-953. PMid: 7855330.

[22] Levine S. Cancer and myositis: new insights into an old association. Myositis and myopathies. Curr Opin Rheumatol. 2006; 18: 620-624. PMid: 17053509. http://dx.doi.org/10.1097/01.bor.0000245721.02512.77

[23] Bronner IM, Hoogendijk JE, Wintzen AR, et al. Necrotising myopathy, an unusual presentation of a steroid-responsive myopathy. J Neurol. 2003; 250: 480-485. PMid: 12700915. http://dx.doi.org/10.1007/s00415-003-1027-y

[24] Pluk H, van Hoeve BJ, van Dooren SH, et al. Autoantibodies to cytosolic 5'-nucleotidase 1A in inclusion body myositis. Ann Neurol. 2013; 73(3): 397-407. PMid: 23460448. http://dx.doi.org/10.1002/ana.23822 